\title{
Fenomenologia, movimento humano e a educação física.
}

\author{
Aguinaldo Cesar Surdi * \\ Elenor Kunz **
}

\begin{abstract}
Resumo: A fenomenologia tem como princípio fundamental o "retorno às coisas próprias", isto é, voltar ao mundo préreflexivo, ou ainda, ao próprio sujeito do conhecimento. Este artigo tem como objetivo mostrar que a fenomenologia, como fundamentação filosófica, contribui para ampliar o entendimento do movimento humano como fator significativo para o ser humano. A teoria fenomenológica possibilita compreender o movimento humano como um diálogo entre o homem e o mundo, considerando o mundo vivido das pessoas como um caminho fundamental para a construção de uma gama de oportunidades significativas, para que o homem crie e recrie seus movimentos. Este movimento possui as características fundamentais para o processo educativo, em que o ser humano tem participação efetiva em sua construção.

Palavras-chave: Fenomenologia. Movimento humano. Educação física.
\end{abstract}

\section{INTRODUÇÃo - FundAMENTOS dA FENOMENOLOGIA}

Quando a fenomenologia fala de mundo ela se refere ao mundo de cada um. Enquanto se relaciona com a realidade, que é aprendida pelos sentidos, ela se torna vivência. Neste sentido, a fenomenologia abre espaço para pensar a realidade humana. Edmund Husserl (2001) foi o precursor da fenomenologia, seu propósito principal foi compreender o mundo como fenômeno, ou seja, mostrar como ele se apresenta a nossa consciência. Fenômeno é tudo o que aparece na consciência e que pode ser aprendido antes de qualquer reflexão. Isto só pode acontecer em nosso mundo vivido através de nossas

*Professor da Graduação em Educação Física. Departamento de Ciências Humanas e Sociais. Doutorando em Educação Física pela UFSC. Universidade do Oeste de Santa Catarina .Videira, SC, Brasil. E-mail: aguinaldosurdi@yahoo.com.br

**Professor da Graduação e da Pós-Graduação em Educação Física. Departamento de Educação Física. Doutor em Educação Física. UFSC. Florianópolis, SC, Brasil. E-mail: elenkunz@terra.com.br 
experiências e vivências cotidianas. A realidade é como o fenômeno, brota na consciência como uma tentativa de representar todo o conjunto de coisas incompreensíveis em si mesmas. A fenomenologia busca esta volta às coisas próprias, ou seja, a volta ao sujeito do conhecimento.

A fenomenologia identifica o que existe de único na existência humana, ao reconhecer que o homem se faz num certo tempo e lugar, com um determinado tipo de experiência. Segundo Carvalho (2007) a noção de mundo, da vida, funciona como o cimento das experiências, e permite dar coerência e compreensão àquilo que se percebe, embora não esteja numa organização lógica. A fundamentação do conhecimento tem início na experiência. Neste sentido que Merleau-Ponty fala sobre o pré-reflexivo e do prépredicativo, dando importância a este mundo da vida, que entende cada pessoa como sendo singular, em que a existência é uma criação que se realiza a cada dia.

Este mundo da vida, ou mundo vivido, que é a tradução da palavra alemã (Lebenswelt), é um termo utilizado por Husserl (2001) para designar o mundo da experiência humana que é considerado antes de qualquer tematização conceitual. Segundo Japiassu e Marcondes (1996, p. 190) o mundo da vida é o que se aceita como dado, como pressuposto e que constitui nossa experiência cotidiana. "Trata-se do real em seu sentido pré-teórico e pré-reflexivo". Husserl (2001) comenta que a reflexão deve começar por retornar a descrição do mundo vivido. Neste sentido, Merleau Ponty (1971) procura encontrar um fundamento anterior ao mundo pensado. $\mathrm{Na}$ nossa experiência do dia a dia predomina os atos inconscientes e não os conscientes. Segundo Carmo (2004) é este o motivo pelo qual Merleau Ponty emprega em suas obras termos como retornar, reencontrar, recolocar, restituir e outros que procuram mostrar a importância de buscar a experiência pré-consciente.

Como exemplo ilustrador do entendimento do conceito de préreflexivo, Carmo (2004) comenta sobre a experiência infantil. A criança antes de pensar e perceber o mundo a sua volta, ela percebe exatamente este mundo antes de ser refletido pelo nosso pensamento.

Movimento, Porto Alegre, v. 16, n. 04, p. 263-290, outubro/dezembro de 2010. 
Salienta ainda que este processo que se inicia no mundo anterior à reflexão (mundo pré-reflexivo) é que fornece os argumentos para que possamos entender o processo de conscientização. Sendo assim, para que possamos começar a refletir sobre as coisas mesmas, devemos fazer um esforço no sentido de eliminar as formas de préconceitos e pré-juízos.

O homem assim constrói seu mundo e o faz se relacionando. A consciência que é sempre intencional é direcionada ao mundo que, por sua vez, se direciona ao homem. Tanto homem como mundo só existem porque são direcionados um para o outro. Por isto a fenomenologia critica a ciência moderna, por simplificar a realidade através de um método de verificação e ignorar o mundo da vida das pessoas. Mundo este que possui uma riqueza de experiências e vivências, que são diferentes como todo ser humano é em sua natureza.

A apreensão das experiências, que os indivíduos adquirem no mundo da vida, possibilita compreender melhor o mundo e a si mesmo. A partir desta compreensão o indivíduo adquire um potencial reflexivo para transformar o mundo que o rodeia e melhorar sua vida. Este poder de reflexão é que torna o indivíduo autônomo e crítico sobre a realidade que vive. A tomada de consciência sobre o mundo é um fator decisivo que proporciona ao ser humano ser sujeito de suas ações.

Nestas experiências se encontra o mundo de movimento dos indivíduos, que possibilita a comunicação do ser humano com seu mundo. Mas como é tratado o movimento humano das pessoas atualmente? A padronização constante dos movimentos é um exemplo claro que o ser humano está fora do processo. A pessoa é apenas um objeto executor de movimentos pré-estabelecidos e direcionados para esportes, danças, lutas e outras formas de destreza motora. $\mathrm{Na}$ escola não é diferente, as crianças têm que se adaptar a normas e regras ditadas pelo professor e/ou treinador. Assim podemos perceber que o ser humano não está no centro do processo do conhecimento, como deseja a fenomenologia, não produz, não utiliza suas experiências e vivências, nem mesmo seu poder de criação e

Movimento, Porto Alegre, v. 16, n. 04, p. 263-290, outubro/dezembro de 2010. 
construção, ou seja, seu mundo da vida é negado. Parece que todas as experiências motoras realizadas até aquele momento não têm nenhum significado no ato da aprendizagem. A partir destas experiências e vivências é que o conhecimento deve progredir e ser reelaborado e resignificado diariamente.

O objetivo deste artigo é mostrar que a fundamentação filosófica fornecida pela fenomenologia contribui para ampliar o entendimento do movimento humano como fator significativo para o ser humano. Na primeira parte deste artigo são abordadas duas teorias sobre o movimento humano, uma baseada nas ciências naturais, propagada pelo esporte de rendimento, e outra fundamentada na visão fenomenológica. Como consequência desta parte é elaborada uma reflexão, baseada na literatura existente sobre as possibilidades de compreensão do movimento humano como fator significativo, levando em consideração a subjetividade.

\section{FENOMENOLOGIA E A TEORIA DO SE-MOVIMENTAR}

Podemos perceber, atualmente, que o movimento humano é focalizado principalmente em estudos que possuem as ciências do esporte como principal suporte de investigação. Esta forma de compreensão se torna de certa forma restrita, no sentido que se fundamenta muitas vezes na objetividade e na quantificação, vinculando assim ao estudo do movimento humano as análises de causa-efeito baseada na física, o que caracteriza o paradigma empírico-analítico como forma de compreender o movimento humano. Este paradigma, com seus caracteres matemáticos, são o que garantem a cientificidade da abordagem. Para que isto aconteça, esta abordagem deve adequar as pessoas a movimentos préestabelecidos, para que estes sejam quantificados. Portanto, o movimento humano é entendido como um ato puramente físico. Acredita-se que esta forma de entender o movimento humano traduz um reducionismo, que exclui características importantes do homem em movimento.

Movimento, Porto Alegre, v. 16, n. 04, p. 263-290, outubro/dezembro de 2010. 
Baseado no trabalho de Buytendijk e sua teoria do movimento humano, Hildebrandt (2001, p. 99) identificou dois paradigmas de entendimento do movimento humano. Um desses paradigmas está relacionado com as ciências naturais, ou ainda às ciências do esporte, que entende o movimento humano apenas "[...] como um deslocamento do corpo físico no tempo e no espaço". Desta forma a exterioridade do movimento é privilegiada. Aquilo que é visível e com possibilidade de descrição é o que importa. Tudo o que não pode ser entendido ou pesquisado de forma empírica e analítica não tem significado, como, por exemplo, o aspecto interno do movimento humano e sua intencionalidade. Sendo assim, as pesquisas são desenvolvidas com base na biomecânica, biologia e fisiologia, que buscam no movimento sua eficácia, otimização e padronização na melhoria de resultados. Os movimentos esportivos têm grande importância neste sistema. Seus movimentos devem ser ordenados conforme padrões de resultados e normas passíveis de descrição e quantificação. Este paradigma para o autor é antipedagógico, e para justificar sua posição ressalta duas implicações:

a) Essa visão de movimento tem um pré-conhecimento do que é movimento correto. Este pré-conhecimento depende, de um lado, das predeterminações dos desportos e, de outro lado, é produzido pela própria teoria que segue o objetivo estipulado para a otimização do movimento (como a minimização do tempo e a maximização da distância). O modelo desses movimentos corretos é encontrado nos movimentos dos esportistas de alto nível.

b) A ajuda para cada pessoa no processo de aprendizagem motora prende-se ao objetivo de capacitálas a chegar bem perto daqueles modelos de movimento legitimados biomecanicamente (HILDEBRANDT, 2001 p. 100-101).

Podemos salientar que este paradigma ignora a individualidade de cada pessoa, considera todos como sendo iguais, com seus corpos e articulações ideais para copiar qualquer movimento externo. $\mathrm{O}$ movimento e a sua aprendizagem não são mais do aluno, mas do

Movimento, Porto Alegre, v. 16, n. 04, p. 263-290, outubro/dezembro de 2010. 
professor. O professor fornece o movimento a ser imitado e gradativamente oferece o feedback ao aluno, para que ele execute de forma correta. O aluno, portanto, está fora do seu próprio movimento. Todo o arcabouço das vivências motoras extraclasse é uniformizado e as diferenças minimizadas. $\mathrm{O}$ que pode acarretar num diretivismo extremo em que o poder centralizador fica sempre com o professor. $\mathrm{O}$ aluno, neste sentido, perde um espaço criador de dar um sentido diferente aos seus atos no decorrer das atividades de movimento e relacionar com suas experiências vividas.

Para Fensterseifer (2001) as ciências naturais limitaram o entendimento do homem e de seu corpo. Retiraram dele toda a possibilidade para compreender as dimensões sociais (prático-moral) e subjetivas (estético-expressiva), que caracterizam o lado humano do homem. O homem perdeu sua historicidade e foi reduzido a um objeto anátomo-fisiológico. Homem este, alienado pelo sistema capitalista, obedecendo à ideologia burguesa que o desloca das suas reais e necessárias relações sociais.

Para Trebels (2006, p. 33) no plano da teoria científica, em que se manifesta o modelo causal-analítico, de investigação do movimento humano, as leis mecânicas interpretam o movimento humano como sendo uma máquina, e equiparam os biomecânicos a engenheiros. A consequência desta interpretação para o autor é a "mortificação do organismo vivo". Comenta ainda que esta relação de causa-efeito é aqui compreendida e orientada para os efeitos, sem um objetivo definido e sem intenções significativas para o ator do movimento, ou ainda, o sujeito do movimento.

Neste caminho de crítica ao paradigma das ciências naturais, Kunz (1991) comenta que o problema deste paradigma é a interpretação puramente técnica do movimento humano, o que fornece um conhecimento muito simples deste movimento, escondendo suas principais possibilidades e potencialidades diante do mundo. Assim, o importante não é mais o ser humano que realiza o movimento, mas o padrão de movimento a ser copiado.

Movimento, Porto Alegre, v. 16, n. 04, p. 263-290, outubro/dezembro de 2010. 
Esta padronização irrefletida dos movimentos dos esportes de competição penetrou na escola e principalmente nas aulas de educação física, desenvolvendo os princípios da "[...] sobrepujança e das comparações objetivas que como consequiências imediatas foram implantadas as tendências do selecionamento, da especialização e da instrumentalização" (KUNZ, 1991, p. 165). Estas tendências criadas pelo esporte competitivo confirmam o caráter antipedagógico deste paradigma, que exclui o humano do movimento humano. A participação da pessoa que executa o movimento deve ser enfatizada. Sua intenção e o sentido desenvolvido por ela devem ser levados em consideração por professores. É nesta participação que o movimento possui as reais condições de ser humano, no sentido de possuir características de uma criação própria.

Trebels (2006) também enfatiza que esta orientação fornecida pelo esporte competitivo é limitada e fornece uma interpretação puramente técnica para o se-movimentar do ser humano. Valorizase apenas o número para determinar o ranking de rendimento esportivo nas várias modalidades. Como consequência, o esporte virou alvo de experimentação, desenvolvida em laboratórios bem equipados, com cientistas preparados nas mais avançadas tecnologias com intenção de preparar corpos fortes para quebrar recordes e superar os limites humanos. Aqui o ser humano é tratado como um meio para se chegar a um fim, muitas vezes desumano.

Neste sentido Santin (1987) comenta sobre os componentes intencionais externos do movimento humano. Estes componentes são objetivos que devem ser alcançados na execução do movimento humano, o que torna este movimento instrumentalizado. Os resultados deste movimento são diferentes do próprio movimento. O movimento se torna um trampolim ou, como citado anteriormente, um meio para se chegar a fins desconhecidos e externos, muitas vezes longe dos reais desejos dos praticantes. Estes condicionantes externos do movimento, levam o ser humano ao simples fazer e atender a objetivos externos, sem significação nem sentido para quem se movimenta.

Segundo Surdi (2010), todo o movimento analisado e discutido até o momento mostra que o ser humano é educado para realizar

Movimento, Porto Alegre, v. 16, n. 04, p. 263-290, outubro/dezembro de 2010. 
tais movimentos baseados numa ordem externa a ele. Geralmente, ele deve obedecer a um padrão preestabelecido, como por exemplo, no esporte. Este caráter de adestramento é fundamental para entender as limitações deste paradigma, que procura entender e interpretar o movimento humano. Esta busca desenfreada pela superação ignora o ser humano, ou seja, o humano do movimento humano. Todas as pessoas são diferentes em inúmeros fatores e é isto que temos que destacar.

Certo padrão de movimento não pode conceber, ou ainda abarcar, todas as possibilidades da individualidade humana. O que deve acontecer é exatamente o inverso, quem deve se adaptar não é o ser humano ao padrão, mas sim o padrão que deve sofrer alterações para que o ser humano possa se expressar significativamente e criar novas possibilidades. $\mathrm{O}$ padrão deve ser construído pelo ser humano, para que este consiga ser o fim de seu movimento intencional.

Baseado nestas importantes colocações, Hildebrandt (2001) identificou outro paradigma o da visão fenomenológica, que é caracterizado como sendo pedagógico. O princípio fundamental desta concepção é a percepção das pessoas se movimentando e nunca o movimento propriamente dito, com suas formas pré-estabelecidas. Baseado neste princípio Tamboer (apud KUNZ, 1991), compreende o movimento humano como sendo uma metáfora, citando que o movimento humano é um diálogo entre homem e mundo. O diálogo que o autor comenta pode ser mais bem entendido quando se diz que o movimento não é nem do homem nem do mundo, mas só pode existir através do relacionamento entre o homem e o mundo. Um é direcionado para o outro. $\mathrm{O}$ movimento se torna a linguagem do homem perante o mundo. Com o movimento o homem se relaciona com tudo o que faz parte do mundo, perguntando e respondendo. $\mathrm{O}$ se-movimentar humano sempre está cheio de intenções. "A intenção, o sentido, que pré-configuramos em relação à avaliação do resultado final, não pode, não deve ser separada do que acontece nas modificações da posição do corpo pelo movimento". (TAMBOER apud KUNZ, 1991, p. 105).

Movimento, Porto Alegre, v. 16, n. 04, p. 263-290, outubro/dezembro de 2010. 
Esta intencionalidade do movimento humano habita todo o semovimentar, por se tratar de homens que se movimentam. Neste movimentar, o homem conhece o mundo a sua volta e se conhece a si mesmo. Dentro deste diálogo ele identifica significações e o sentido das coisas e das outras pessoas. O movimento é uma forma de conhecimento que nos possibilita identificar o significado do próprio movimento. Esta relação dialógica entre homem e mundo possibilita a construção de movimentos, que recebem significações e sentidos apropriados para cada execução.

O se-movimentar proporciona um mundo de significações motoras. Estas significações são intencionais e deve no dizer de Tamboer (apud KUNZ, 1991, p. 175) "transcender limites". Para o autor, o movimento humano intencional pode ser adquirido baseado em três formas diferentes. A primeira é a forma direta, em que a transcendência acontece na base da intencionalidade espontânea das pessoas como uma ação não pensada. Esta forma está relacionada com o plano pré-reflexivo, ou seja, as respostas são fornecidas livremente e espontaneamente ao mundo. Como exemplo, Kunz (1991) cita os primeiros contatos de uma criança com a bola. Ela sabe o que fazer com a bola e gradativamente vai brincando através do chutar, rebater, quicar e com isto vai dialogando com o mundo, construindo o seu mundo de significações.

A segunda forma é a apreendida, que surge pela aprendizagem, ou ainda pela intencionalidade que desenvolve através da ideia de imagem do movimento. Nesta forma, a questão principal é fornecer pistas sobre a ideia do movimento para que o problema seja resolvido. Não se quer valorizar a imitação, mas simplesmente incentivar que a pessoa, de forma intencional, possa executar o movimento baseado em poucas informações e assim chegar a um fim. Este fim não necessariamente tem que ser o proposto pelo professor, mas próximo a isto.

A terceira forma é a criativo-inventiva, que surge da intencionalidade inventiva e criativa por parte de cada um. A transcendência do mundo é feita a partir da criação e invenção. $\mathrm{O}$ ser humano explora e constitui o mundo com novos significados/

Movimento, Porto Alegre, v. 16, n. 04, p. 263-290, outubro/dezembro de 2010. 
sentidos que the fornecem uma maior compreensão-de-mundo. A partir desta compreensão, o ser humano adquire capacidades para mudar o mundo situacional em que vive e, consequentemente, mudar a si próprio.

Nosso mundo é sempre um mundo vivido. É neste mundo que nossas possibilidades de se-movimentar se tornam humanas e significativas. Para SURDI (2010) nossas experiências originais são fundamentais para que nossa compreensão de mundo seja significativa. Temos que agir e participar ativamente na relação que temos com este mundo. Esta relação se dá, muitas vezes, pelo movimento, e este movimento tem que ser inventivo e individual, pois todas as pessoas são diferentes. Como são diferentes podem compreender o mundo ao seu modo e, desta forma, criar o seu semovimentar, que proporciona uma comunicação com o mundo também significativa.

Os movimentos devem ser experimentados pelo executante através das suas sensações. Baseado na teoria da Gestalt, ou na teoria da percepção, a estrutura do ser humano deve ser considerada. A subjetividade e a intersubjetividade devem ser primordiais na relação entre os seres humanos e o meio ambiente. Esta relação de totalidade entre homem e mundo é fundamental para a existência humana. Para Merleau Ponty (1971), isto quer dizer "estar para o mundo". O homem está para o mundo porque o mundo está para o homem. Esta reciprocidade intencional é o suporte essencial em direção ao entendimento do mundo, de todas as coisas que o habitam e suas respectivas relações.

Neste sentido, como princípios de ensino deste paradigma, podese caracterizar alguns que mostram seu pressuposto pedagógico, o que possibilita uma autonomia de movimento. A problematização de uma situação de movimento leva os alunos a buscar a solução na experiência que cada um tem. Desta forma, a construção de movimentos é fundamental para que o aluno dê significações às suas ações e utilize para isto a experimentação, colocando em evidência seu mundo vivido.

Movimento, Porto Alegre, v. 16, n. 04, p. 263-290, outubro/dezembro de 2010. 
As configurações de situações diferentes são direcionadas para percepções também diferentes. A teoria da Gestalt chama este processo de diferenciação de "centralização da atenção ou centralização da percepção". Esta centralização deve ser considerada em função da coisa e nunca do corpo. Desta forma, o processo de aprendizagem deve se apresentar como um processo subjetivo, humano e aberto às experiências individuais.

A fenomenologia busca superar o pensamento dualista, através do descobrimento da reciprocidade relacional entre corpo-mente, mundo-homem e etc. Neste sentido, Merleau Ponty (1971) explica que meu corpo não é alguma coisa que eu tenho, mas sim que eu sou meu corpo. A relação que tenho com os outros pela forma de olhar, gestos, mímicas, e outras possibilidades, são manifestações corporais que me revelam como ser humano. O corpo não é uma coisa inerte sem significado, nem um obstáculo a ser transposto, mas parte integrante da totalidade do ser humano. Segundo Aranha e Martins (1996), ao ver as pessoas se movimentando, não posso relacionar apenas como um ato mecânico, como se fosse uma máquina, mas sim, como gesto expressivo de um sujeito que busca se comunicar com o mundo. $O$ gesto neste sentido não é apenas corporal, mas sim, fornecedor de significado que vai em direção ao sujeito e à sua interioridade.

Desta forma, pode-se dizer que o corpo e suas manifestações por meio de seus atos e movimentos são os primeiros momentos de experiência humana. O sujeito é um ser que vive e sente primeiramente, para depois ser um ser que conhece. Assim é a maneira de participar com o corpo e com suas diversas formas de movimento no conjunto da totalidade da realidade humana.

Kunz (2000) enfatiza a percepção, a sensibilidade e a intuição humana, como sendo fatores da fenomenologia de suma importância. A percepção do movimentar-se possibilita a melhoria da qualidade deste movimento no tempo e no espaço. A sensibilidade procura lidar com os objetos, os outros e consigo mesmo. A intuição proporciona ao ser humano sentir de forma antecipada os resultados esportivos, além de nossa presença corporal na atividade. Para

Movimento, Porto Alegre, v. 16, n. 04, p. 263-290, outubro/dezembro de 2010. 
este autor a percepção, as emoções e os sentimentos, são fundamentais para entender o "se-movimentar" e sua relação com o mundo vivido. Trebels citado por Kunz (1991, p.163) afirma que "[...] movimento é, assim, uma ação em que um sujeito, pelo seu se movimentar, se introduz no mundo de forma dinâmica e através desta ação percebe e realiza os significados/sentidos em e para o seu meio".

Para Gonçalves (2001), o homem é totalidade através da corporeidade. A corporeidade e o mundo formam uma unidade que deve ser compreendida como sendo anterior ao pensamento e à reflexão. Nesta ótica, não existe separação entre sujeito e objeto. Para a autora, o movimento humano é uma totalidade dinâmica que se reestrutura a cada instante, expressando uma intenção entre um sujeito com o mundo. O sentido do movimento é subjetivo e objetivo ao mesmo tempo. A intenção do movimento é o fator totalizador que desenvolve no sujeito a percepção de seus próprios movimentos. A corporeidade só pode ser compreendida como vivência humana que pretende fazer com que o mundo apareça para nós através de nossa consciência. A expressão, podemos considerar, a operação da intencionalidade. No conceito de expressão, o sensível possui um sentido imanente, ou seja, o sentido habita o objeto. O corpo se caracteriza pela sua possibilidade de movimento. Este corpo, entendido como sendo corpo-sujeito, se movimenta como uma intencionalidade que percebe as coisas vivendo-as. Este movimento vivo e livre, podemos dizer que é um ato expressivo, significativo e único. A expressão pode ser realizada através do nosso corpo. Ela tem a capacidade de revelar o sentido de nossas experiências puras.

O movimento caracterizado no esporte é influenciado fortemente pelo progresso técnico e científico, justificado pelo rendimento, concorrência e competição. Na área da educação física esta visão reduz a relação homem-mundo e o prazer em se-movimentar. Os movimentos esportivos interpretados tecnicamente minimizam o poder de significação, principalmente, da criança e do adolescente do seu próprio se-movimentar. Temos que ressaltar que não é o esporte em si que padroniza os movimentos, mas sim o que é feito do esporte

Movimento, Porto Alegre, v. 16, n. 04, p. 263-290, outubro/dezembro de 2010. 
para que isto aconteça. O esporte pode ser um fator muito significativo na criação de formas diversificadas de prática, que pode oferecer oportunidades subjetivas e individualizadas aos praticantes.

Conforme Kunz (1994) deve-se ampliar as reflexões sobre o diálogo entre homem e mundo, enfatizando, por exemplo, o semovimentar como acontecimento fenomenológico, ou seja, relacionando de forma intencional com ações significativas e que estas ações tenham consequências educacionais para a vida. Neste sentido, o autor comenta que:

\begin{abstract}
Não se trata de formar pessoas que se conheçam melhor, apenas, mas de formar gente consciente de que jamais conhecerá tudo de si, pois isso consiste em conhecer a humanidade e o mundo. É imprescindível desencadear um processo de conhecimento de si através dos valores humanos encontrados em cada indivíduo, possibilitando condições para que cada aluno e aluna encontrem, por suas referências internas e não apenas do mundo exterior o dos outros, o que ele ou ela de fato são em relação ao mundo, aos outros e a si próprio. (KUNZ, 1994, p. 5)
\end{abstract}

Hildebrandt (2001) traça quatro princípios de ensino que fazem este paradigma do movimento humano ser mais bem entendido como pedagógico:

1)Um pressuposto fundamental para uma aprendizagem motora que considera esta ligação do homem e mundo como dialógica, é a possibilidade de configuração motriz autônoma e livre de normas predeterminadas. O importante no ensino são os períodos de procura autônoma dos alunos. É preciso dar uma abertura ao processo de ensino e aprendizagem. A exploração do problema resulta da experiência, o professor tem o conhecimento das soluções e fundamentações encontradas pelos alunos.

2)Um segundo princípio é o da totalidade. Isto significa: oferecer aos alunos os movimentos que eles possam realizar como uma totalidade desde o início.

Movimento, Porto Alegre, v. 16, n. 04, p. 263-290, outubro/dezembro de 2010. 


\begin{abstract}
3)Usar metáforas na informação verbal. Da aprendizagem motora, sabemos que, na fase de desenvolvimento da coordenação motora fina e da disponibilidade variável, informações verbais não têm sucesso.

4)Configurar situações diferentes, que são direcionadas para percepções diferentes. A teoria da Gestalt chama esse princípio de diferenciação de centralização de atenção ou centralização de percepção. Muito importante aqui é que cada centralização deve acontecer em relação à coisa e nunca ao corpo. O direcionamento da atenção para os parâmetros da execução corporal de movimento prejudica a evidência da percepção e, com isso, o processo de aprendizagem motora. Esses princípios devem ser considerados pelos professores de educação física, uma vez que o processo de aprendizagem motora se apresenta como um processo subjetivo, humano e aberto para as experiências individuais, pois, sempre vemos homens movimentado-se, nunca formas de movimento. (HILDEBRANDT, 2001, p. 109-110).
\end{abstract}

Para Freire (1981) o educando se apropria do conhecimento, quando ele o redescobre e o relaciona com o mundo vivido concreto. Desta forma pode-se dizer que a verdadeira aprendizagem aconteceu. Sendo assim temos que aproximar a realidade do mundo vivido ao mundo de movimento dos alunos.

\title{
3 IMPLICAÇÕES PARA A EDUCAÇÃo FísICA
}

A educação física escolar faz parte do processo educacional como disciplina obrigatória em vários níveis escolares. Percebemos que mesmo assim ela é, muitas vezes, criticada por outros professores, geralmente de outras disciplinas, acusada de não auxiliar em nada na educação dos alunos. Atualmente o desenvolvimento da educação física escolar se baseia no ensino dos esportes tradicionais, levando em consideração suas regras e técnicas, com a intenção de

Movimento, Porto Alegre, v. 16, n. 04, p. 263-290, outubro/dezembro de 2010. 
superação de limites. Este processo competitivo e excludente é um fator limitador para as infinitas possibilidades educativas do semovimentar humano. Entendo que o esporte pode oferecer grandes possibilidades educativas, contanto que leve em considerações o ser humano.

Segundo Surdi (2010) o direcionamento para a formação crítica e consequentemente participativa de nossos alunos é um fator primordial no sistema escolar atualmente. Temos que ampliar a discussão a este respeito, conhecendo cada vez mais a realidade social da escola, dos alunos e dos envolvidos no processo educacional, para que o conhecimento produzido consiga atingir seus objetivos, de melhorar a vida das pessoas. Na educação física escolar o esporte ainda está em pleno destaque, principalmente o esporte de alto rendimento, que serve de modelo para as práticas esportivas na escola. A crítica a esta educação física esportivizada é que, além de reforçar nos alunos os ideais do capitalismo selvagem, ele se torna um mero recebedor e imitador de informações motoras. O seu movimento é controlado pelo professor que toma todas as decisões de como, quando e por que o aluno deve movimentar-se.

O sistema esportivo oferece uma resposta específica ao problema do movimento do ser humano. Desta forma, pode-se dizer que o esporte busca a simplificação do movimento humano em poucos níveis, que se traduz em modelos que igualam as pessoas. Hildebrandt (2001) salienta que o mundo de movimento do ser humano é complexo e apresenta vários níveis, por ser cada ser humano único e possuidor de uma cultura de movimento que é individual. $\mathrm{O}$ autor comenta que esta simplificação está relacionada à obediência às regras de cada modalidade esportiva, que são pré-determinadas para realização de determinada atividade. Aeducação física escolar tem que agir contra o sistema de simplificação do movimento, acentuado pelo sistema esportivo. Ela pode oportunizar aos alunos o entendimento do esporte para que depois eles possam mudá-lo de acordo com seus interesses e necessidades, conforme suas experiências de movimento.

Segundo Kunz (1994) o movimento humano é o principal conteúdo do trabalho pedagógico da educação física. Com isto ele

Movimento, Porto Alegre, v. 16, n. 04, p. 263-290, outubro/dezembro de 2010. 
considera quatro concepções básicas de como a educação física vem sendo trabalhada nas escolas. A primeira é a concepção biológicofuncional, que prioriza como conteúdo de ensino o exercício físico. A função da educação física é melhorar o condicionamento físico dos alunos, para com isto aprimorar a saúde da população. A segunda concepção ele denominou de formativo-recreativa, em que a educação física deve auxiliar na formação social do aluno, adaptando suas exigências às exigências da sociedade. As atividades desenvolvidas nesta concepção estão relacionadas à espontaneidade e ao prazer, priorizando os aspectos lúdicos do movimento. A terceira concepção ele denomina de técnico-esportiva, que considerada a mais difundida nas escolas atualmente, como já comentamos anteriormente. Esta concepção baseada no sistema esportivo procura o talento esportivo, através da adaptação às exigências motoras do esporte de alto rendimento. A quarta concepção defendida pelo autor é a crítico-emancipatória, que entende o movimento humano como possibilidade de expressão e comunicação.

Na concepção crítico-emancipatória, a educação física é o caminho pelo qual o se-movimentar pode ser entendido como forma de linguagem que possibilita um conhecimento mais reflexivo do mundo. $\mathrm{O}$ educando deve ser o centro do processo educativo, ele deve ser ativo e participativo como sujeito pensante. O se-movimentar deve partir do aluno através de um processo de construção e problematização, em que o aluno utiliza o seu repertório cultural de movimento para produzir uma comunicação significativa com o mundo. "O aluno enquanto sujeito dos movimentos intencionados na aprendizagem e não a modalidade esportiva deve estar no centro de atenção do ensino." (KUNZ, 1994, p. 127).

Neste sentido o esporte deve sofrer mudanças que atendam às necessidades e anseios dos alunos e nunca ao contrário. $\mathrm{O}$ esporte tem que ser tematizado em função do mundo vivido de cada pessoa. Este questionamento contextualizado do esporte permite ampliar o conceito e o entendimento do esporte como um fenômeno sociocultural e histórico. Esta amplitude no conceito de esporte segundo Kunz (1994) deve abranger expressões como cultura de

Movimento, Porto Alegre, v. 16, n. 04, p. 263-290, outubro/dezembro de 2010. 
movimento, mundo de movimento e ainda atividades lúdicas. Estas expressões mostram que o homem em movimento deve ser entendido como produtor de cultura, que tem história, que tem vida e que possui poder para participar ativamente nas tomadas de decisões. Assim podemos dizer que não é o aluno que tem que se adaptar às regras do esporte de alto rendimento, mas sim as regras devem ser questionadas e transformadas em função das diferenças individuais dos alunos e das decisões tomadas coletivamente no interior das aulas de educação física.

Desta forma Hildebrandt (2001) faz um paralelo sobre as consequências de se trabalhar numa aula de educação física com um conceito de esporte tradicional, baseado no sistema esportivo e uma concepção pedagógica crítica, na qual o aluno tem possibilidades de modificar a forma de praticar determinado esporte. Enquanto no conceito de esporte existe uma separação entre os âmbitos da vida, a concepção crítica possibilita uma orientação para o mundo da vida, descobrindo e conhecendo cada vez mais os ambientes que fazem parte da sua vida de forma ativa. Os espaços para realização dos movimentos são específicos no conceito de esporte, como ginásios, quadra de futebol, piscina de natação. Enquanto na proposta crítica as aulas de educação física devem se relacionar com as outras disciplinas, possibilitando uma aprendizagem interdisciplinar, valorizando o ser humano em ação significativa. Na concepção crítica, os temas são tratados de forma global como embalar, balançar, homem na água, equilibrar e outros. Percebe-se nesta questão a importância pelo respeito às diferenças individuais. Outro fator importante é sobre a separação dos alunos, baseado em critérios físicos, feito pelo sistema esportivo. Numa concepção crítica, a prioridade é conciliar aulas co-educativas que oportunizem a participação de pessoas de várias idades. No esporte é realizada também uma separação das pessoas em função do grau de habilidade motora. Na proposta crítica é oferecida uma oferta variada de movimentos, com diferentes significados que parte de quem está realizando o movimento. Por fim, enquanto o esporte enfatiza o treinamento com intenções competitivas e de superação de um adversário, a proposta crítica oportuniza a aprendizagem através de

Movimento, Porto Alegre, v. 16, n. 04, p. 263-290, outubro/dezembro de 2010. 
experiências de movimento, propiciando um entendimento subjetivo e significativo para quem executa o movimento.

Estas comparações mostram que o sistema do esporte, entendido como sendo de alto rendimento, possui um papel reprodutor e acrítico da sociedade, não atendendo aos principais objetivos e anseios educacionais, mas que hoje ainda permeiam o trabalho no interior da escola e principalmente da educação física. Este sistema esportivo se apoia em três tendências. A primeira é a tendência para a seleção, atender apenas os melhores. A segunda é a tendência para a especialização, focar todos os esforços em uma prova ou modalidade para atingir o máximo rendimento. E a última tendência é para a instrumentalização, que entende o corpo como um instrumento físico e mecânico, sempre pronto a suportar cargas.

Estas tendências do sistema esportivo não levam em consideração o principal fator pedagógico e, consequentemente, educacional, que caracteriza o se-movimentar como uma relação dialógica entre homem e mundo, que é o contexto de vida das pessoas. O sistema esportivo elimina o ser humano do movimento, o importante são as formas padronizadas de movimento que devem ser executadas com o mínimo de gasto de energia e em menor tempo possível. Nas aulas de educação física o professor deve oportunizar um ambiente propício para que os alunos participem das aulas, para que eles vivenciem suas experiências motoras construídas no dia a dia. A transformação de atividades por parte dos alunos já é um motivo para que eles construam sua subjetividade de forma mais autônoma e crítica.

A aula de educação física deve ser entendida como um processo de interação em que professor e aluno definem suas ações e com isto os significados, que são diferentes para cada aluno. A educação deve estar interessada no aluno e compreendê-lo como sujeito capaz de atuar e colocar em prática suas ideias e criações. Desta forma, como a educação poderia ser desenvolvida para oportunizar aos seus alunos a possibilidade de ser sujeito de sua ação? Hildebrandt (2001) classifica as aulas de educação física como sendo fechadas e abertas. Fechadas quando as decisões e definições são colocadas

Movimento, Porto Alegre, v. 16, n. 04, p. 263-290, outubro/dezembro de 2010. 
de forma unilateral pelo professor. Já o ensino aberto abre as possibilidades de comunicação e participação de forma efetiva do aluno no decorrer da aula, que toma as principais decisões durante a mesma.

A compreensão de aula fechada retrata muito bem a realidade da educação física hoje. O professor é o detentor do poder e do saber e passa para o aluno o conhecimento que lhe interessa e que será mais importante para ele do que para o aluno, que irá semovimentar. Nesta ótica, percebe-se a redução deste movimentarse humano, que entende a aprendizagem de destrezas motoras como o principal conteúdo da aula, e o objetivo deste conteúdo está fora das necessidades individuais de cada aluno. Este processo mecânico e irrefletido, que acontece na escola, mostra um militarismo disfarçado, o professor tem a voz de comando e os alunos a simples tarefa de obedecer.

O esporte de rendimento se tornou o modelo de esporte para toda a sociedade. Percebe-se hoje na escola um número cada vez maior de competições entre alunos e escolas, que denominam desporto educacional. Estas competições esportivas fortalecem ainda mais os objetivos e conteúdos da educação física escolar. As aulas se tornaram treinos esportivos para determinada competição. $\mathrm{O}$ desenvolvimento do esporte de alto rendimento na escola atualmente é uma questão de bastante discussão entre profissionais da área. A disseminação desta forma de prática esportiva entre os alunos produz rivalidades e aflora uma competitividade cada vez maior entre escolas, como se as vitórias fossem uma forma de categorizar as escolas em melhores e piores. Desta forma temos que repensar o esporte e transformá-lo em processo para se chegar a fins educativos (SURDI, 2010).

A concepção de aulas abertas entende o processo educacional como sendo comunicativo, em que o professor abre espaço para que o aluno possa definir suas próprias situações e expressar seus significados subjetivos. O movimento humano neste caso fica acessível à interpretação e a configuração individual. Não existe preocupação com as formas de movimento, mas sim com a construção

Movimento, Porto Alegre, v. 16, n. 04, p. 263-290, outubro/dezembro de 2010. 
individual desta forma pelos alunos. Esta possibilidade segundo Rotth (apud HILDEBRANDT, 2001) é denominada de ação exploratória, fundada na antropologia pedagógica. Na teoria da Gestalt, Metzger (apud HILDEBRANDT, 2001) esclarece que este processo é chamado de liberdade criativa. Hildebrandt (2001) fundamenta esta concepção aberta de ensino da seguinte forma:

\begin{abstract}
Ela encontra-se fundada por um lado em uma concepção de homem atuante, como um ser principalmente autônomo e responsável socialmente. Por um lado, sigo com minhas reflexões a compreensão básica interacionista, a partir da qual os homens desenvolvem os seus significados do mundo somente em confrontações sociais. Esse processo da confrontação é apoiado através da aula, onde o princípio de negociação comunicativa é colocado no princípio de imposição. Somente em um processo social que permite processos autônomos de confrontação, torna-se possível uma aprendizagem consciente e crítica, no sentido de uma liberação consciente de pressões internas e externas. (HILDEBRANDT, 2001, p. 48-49)
\end{abstract}

O movimento dentro de uma concepção de aula fechada é entendido como sendo regulamentada para ser copiada por todos, sempre seguindo um modelo. Na concepção aberta este procedimento é apenas descrito em forma de problemas ou através de uma intenção. Sendo assim, fica aberto como o problema proposto vai ser resolvido. A problematização nas aulas é um fator determinante no processo educativo aberto. A exploração na resolução do problema resulta das experiências dos alunos, baseada no seu mundo de movimento. Dentro de uma aula de educação física problematizadora, teremos muitas respostas diferentes, que são interpretadas individualmente.

O professor tem um papel importante na construção de temas que possibilitem problematizações. Como exemplo para uma aula de educação física, podemos citar um tema como o arremesso. A partir deste tema surgem inúmeros questionamentos que cada aluno irá resolver a sua maneira. Podemos perguntar como podemos

Movimento, Porto Alegre, v. 16, n. 04, p. 263-290, outubro/dezembro de 2010. 
arremessar um objeto? Para arremessar mais alto o que podemos fazer? E mais longe? Que diferença tem em arremessar objetos de vários tamanhos e pesos? Como podemos construir um jogo que envolva arremessar e que todos possam jogar? Podemos perceber que até agora não foi mencionado nada sobre o arremessar ter relação com algum tipo de movimento técnico esportivo. Aqui o respeito foi com o indivíduo, com a sua subjetividade e as experiências do dia a dia de cada aluno. $O$ processo criativo dos alunos foi aguçado e assim as formas de movimentos que foram criadas possuem um significado para ele, pois ele faz parte desta criação.

Santin (1987) salienta a importância dos componentes intencionais internos, primeiramente por se confundirem com os próprios movimentos e segundo por serem fundamentais para entender o movimento humano significativo. Estes componentes entendidos intencionalmente são o que dão segundo o autor "a verdadeira identidade e autonomia da educação física". (SANTIN,1987, p. 37). Ele cita alguns componentes como a expressividade, que constitui a linguagem corporal como gesto, que mostra de forma significativa que o homem está presente no mundo. Outro é a competitividade, todo movimento humano é competitivo. Para entendermos de forma intencional interna a competição, seu direcionamento deve ser na busca de seu próprio equilíbrio, da sua harmonia e da sua beleza, e não para provar a superioridade na comparação com os outros. O prazer é um componente que mostra a satisfação do indivíduo na realização do movimento. Outro componente, a premiação, citado pelo autor, também deve ser interpretado de forma que a recompensa principal seja sentida internamente pelo indivíduo, pelo simples fato de ter feito. As medalhas, troféus e outros devem ficar em segundo plano. Por fim, o componente produtividade, que deve ser compreendida como uma ação feita que nos agrada, porque temos o desejo de fazer o movimento.

As mudanças na educação física escolar, para que o movimento humano seja entendido de uma forma mais humana, deve atingir as concepções de conteúdos, de ensino e a relação professor-aluno.

Movimento, Porto Alegre, v. 16, n. 04, p. 263-290, outubro/dezembro de 2010. 
Não só a educação física, mas toda a escola deve estar aberta às possibilidades de participação efetiva dos alunos no processo educacional. As experiências que os alunos trazem de casa devem ser valorizadas e, a partir delas, novos conteúdos contextualizados devem ser transmitidos de forma crítica, através da problematização, para que o aluno consiga entender todas as questões que envolvem tal conteúdo e fazer relações significativas que melhorem sua vida.

Na concepção de conteúdo devemos privilegiar o movimento humano como possibilidade ilimitada do se-movimentar, ao invés das tradicionais formas padronizadas de movimento. O mundo de movimento vivido pelos alunos merece um papel importante neste sentido. É ele que vai fornecer inúmeras possibilidades de semovimentar de forma autônoma e significativa. Segundo Kunz (1991) se assim for concebida a aula de educação física, ela será permeada por múltiplas perspectivas para o desenvolvimento e a interpretação do movimento. Desta forma, os movimentos normatizados relacionados ao esporte compõem apenas uma parte do mundo de movimento dos alunos.

Na concepção de ensino, pela qual temos que oportunizar o semovimentar do aluno, as aulas abertas a experiências possibilitam uma importante contribuição no sentido de ampliar as possibilidades de decisão do aluno no processo educativo. Como citamos anteriormente, as aulas abertas proporcionam uma maior troca entre professor e aluno, o que oportuniza uma melhor reflexão sobre a realidade. $\mathrm{O}$ professor tem que atuar como um problematizador, aguçando a curiosidade do aluno no desenvolvimento de respostas motoras individuais que sejam respeitadas por todos. $\mathrm{O}$ professor não pode ser um comandante na aula, tomando todas as decisões e mandando o que os alunos devem fazer, mas sim fazer perguntas para que os alunos respondam através do seu se-movimentar, que é intencional e particular, assim teremos muitas respostas para um mesmo problema. O se-movimentar é uma compreensão-do-mundopela-ação, desta forma o processo deve ser entendido como açãoreflexão-ação. Para Kunz (1991) a problematização deve favorecer

Movimento, Porto Alegre, v. 16, n. 04, p. 263-290, outubro/dezembro de 2010. 
para que o aluno se sinta responsável pelas ações de movimento. Neste sentido comenta que:

\begin{abstract}
Em relação à problematização do ensino que envolve o movimento, os alunos devem encontrar possibilidades de solucionar problemas a partir de suas próprias perspectivas, recorrendo sempre às suas próprias experiências e vivências. O educando deve agir pela auto-motivação. Aúnica pré-condição para isto é que o problema a ser solucionado deve ser muito bem esclarecido anteriormente (KUNZ 1991, p. 193).
\end{abstract}

\title{
4 ConsideraçõEs FINAIS
}

A fenomenologia nos mostra outra forma de ver o mundo. $\mathrm{O}$ mundo entendido pela fenomenologia entende as experiências como um processo significativo para compreendê-lo. O entrelaçamento destas experiências, tanto da pessoa como as dos outros, formam uma unidade que une a subjetividade e as intersubjetividades, direcionando assim um entendimento mais global das relações existentes na compreensão do mundo.

Este se-movimentar espontâneo e intencional é fundamental para que o indivíduo se expresse de forma autêntica e livre com relação a tudo o que existe. A partir desta cultura de movimento é que podemos avançar no sentido de ampliar o potencial de movimento das pessoas, mas sempre contextualizando com base na subjetividade. Assim o movimento humano sempre será significativo, pois é a pessoa que se apropria do movimento como sendo gesto expressivo que dialoga com o mundo constantemente e com isto se desenvolve.

O movimento humano significativo vê pessoas se movimentando baseado numa intencionalidade que possibilita ao indivíduo ter consciência do que está fazendo. Neste processo as diferenças individuais entre as pessoas são levadas em consideração, pois elas são livres para se-movimentar e através deste movimento descobrem um mundo de oportunidades muito maior que a simples cópia de movimentos pré-estabelecidos. Esta liberdade possibilita o

Movimento, Porto Alegre, v. 16, n. 04, p. 263-290, outubro/dezembro de 2010. 
desenvolvimento da criatividade na criação de novos jogos e movimentos a partir daqueles que já sabe. Este entendimento mais amplo do movimento humano trata da real compreensão que o ser humano deve ter sobre o seu se-movimentar. O processo de voltar às coisas próprias, defendido pela fenomenologia, pode se entender como sendo uma volta ao próprio sujeito. Neste sentido o sujeito deve ser privilegiado no seu movimento que é sempre único e original.

A argumentação fenomenológica permite entender o movimento humano como significativo, quando a compreensão do mundo vivido é valorizada. Os movimentos intencionais das pessoas se tornam expressivos e cheios de sentido. Este movimento prazeroso e criativo possibilita que o ser humano se conheça cada vez mais. O sentimento humano e as vivências anteriores são fatores importantes na contextualização e crítica das formas e padrões de movimentos que são impostos.

A escola, a educação física e os professores de educação física devem entender este processo fenomenológico de compreensão do movimento humano como sendo pedagógico, e lidar com seus alunos de tal forma que amplie a possibilidade do se-movimentar, que privilegie o movimento próprio de cada um.

Os professores de educação física são fundamentais para que estas importantes transformações educacionais aconteçam. A formação técnica que ainda predomina nos cursos de graduação não consegue oferecer uma reflexão que vá além dos manuais de exercícios e análises biomecânicas de movimento. Ainda estudamse formas de movimento e como o ser humano pode se adaptar a elas de forma mais precisa e rápida. Esta limitação do movimento próprio nos torna presa fácil no processo de alienação e dominação social. Os professores devem procurar entender de forma mais ampla o sentido do movimento humano. Este procedimento só pode ser feito através de um engajamento em estudos baseados na filosofia e sociologia, só que a maioria dos professores ainda não consegue ver relação entre estas disciplinas e a educação física. Comentam ainda que a filosofia não serve para nada, porque com ela não se chega a lugar nenhum. Este trabalho procurou mostrar bem o contrário. Com

Movimento, Porto Alegre, v. 16, n. 04, p. 263-290, outubro/dezembro de 2010. 
a reflexão filosófica somos capazes de detectar a real possibilidade que o movimento humano possui como fator determinante na educação das pessoas na busca de sua autonomia.

O ensino problematizador deve ser enfatizado. Os alunos devem ser instigados a se-movimentar de forma própria, a construir e criar novas formas de movimento que estimulem a criatividade e o prazer. Cada movimento é único e particular e deve ser valorizado por todos. $\mathrm{O}$ professor, neste sentido, deve mais perguntar do que oferecer respostas prontas. A multiplicidade de ideias e de respostas favorece um ambiente dialógico. Esta troca dialética de informações entre os alunos, para resolver um determinado problema, mostra que o aluno é o centro do processo da aprendizagem e com isto se acha importante. Desta forma, ele se torna cada vez mais capaz de tomar suas próprias decisões, tanto na sala de aula como fora dela. O movimento do ser humano é o fator mais importante que a educação física possui para se preocupar, com isto, ela deve procurar compreendê-lo em sua totalidade. Deve ampliar seu entendimento sempre, numa busca infinita, porque o movimento humano entendido como significativo é sempre novo. Cada gesto intencionado para o mundo tem sua particularidade que é original de cada sujeito que se expressa da sua maneira. Desta forma, o estudo sobre o movimento humano deve ser mais explorado. O ser humano é movimento e o movimento significativo é o que nos caracteriza neste mundo.

Movimento, Porto Alegre, v. 16, n. 04, p. 263-290, outubro/dezembro de 2010. 
Phenomenology, human movement and Physical Education.

Abstract: Phenomenology has its fundamental principle of "return to things themselves" this is back to the pre-reflective, or even the very subject of knowledge. This article aims to show that phenomenology as a philosophical foundation, helps to broaden the understanding of human movement as a significant factor for humans. The phenomenological theory allows us to understand human movement as a dialogue between man and the world, considering the lived world of people as a fundamental way to build a range of significant opportunities for man to create and recreate their movement. This movement has the characteristics essential to the educational process, where human beings have effective participation in its construction.

Keywords: Phenomenology. Human movement. Physical education.

Fenomenología, movimiento humano y la Educación Física.

Resumen: La fenomenología tiene su principio fundamental de la "vuelta a las cosas mismas" trata de volver a la pre-reflexivo, o incluso el contenido mismo del conocimiento. Este artículo pretende mostrar que la fenomenología como un fundamento filosófico, contribuye a ampliar la comprensión del movimiento humano como un factor significativo para los seres humanos. La teoría fenomenológica nos permite entender el movimiento humano como un diálogo entre el hombre y el mundo, teniendo en cuenta el mundo vivo de las personas como un medio fundamental para construir una serie de importantes oportunidades para el hombre de crear y recrear su movimiento. Este movimiento tiene las características esenciales del proceso educativo, donde los seres humanos tienen una participación efectiva en su construcción.

Palabras clave: Fenomenología. Movimiento humano. Educación física.

Movimento, Porto Alegre, v. 16, n. 04, p. 263-290, outubro/dezembro de 2010. 


\section{REFERÊNCIAS}

ARANHA, Maria Lucia Arruda; MARTINS, Maria Helena Pires. Filosofando: Introdução a Filosofia. 2. ed.. São Paulo: Moderna, 1996.

CARVALHO, José Maurício de. A existência Humana. Revista Filosofia Ciência \& Vida, São Paulo, v. 1, n. 11, p. 34-39, 2007.

CARMO, Paulo Sergio. Merleau -Ponty: Uma Introdução. São Paulo: Editora EDUC, 2004. (Série Trilhas).

FENSTERSEIFER, Paulo Evaldo. A educação física na crise da modernidade. ljuí: Editora Unijui, 2001.

FREIRE. Paulo. Educação e Mudança. 3. ed. São Paulo: Paz e Terra, 1981.

GONÇALVES, Maria Aparecida. Sentir, Pensar, Agir: Corporeidade e Educação. 5. ed.. Campinas, SP: Papirus, 2001.

HILDEBRANDT, Reiner. Textos Pedagógicos sobre o ensino da educação física. ljuí: Editora Unijuí, 2001.

HUSSERL, Edmund, Meditações Cartesianas. São Paulo: Madras, 2001.

JAPIASSÚ, Hilton; MARCONDES, Danilo. Dicionário Básico de Filosofia. 3. Ed. rev. ampl.. Rio de Janeiro: Jorge Zahar, 1996.

KUNZ, Elenor. Educação Física: Ensino \& Mudanças. Livraria UNIJUI Editora. ljuí, RS. 1991.

KUNZ, Elenor. Transformação didático: pedagógico do esporte. 3. Ed.. ljuí: Editora UNIJUI, 1994.

KUNZ, Elenor. A relação teoria/prática no ensino/pesquisa da educação física. Motrivivência, Florianópolis, v. 7, n. 8, p. 46-54,1985.

KUNZ, Elenor.. Esporte: uma abordagem com a fenomenologia. Movimento, Porto Alegre, v.6, n.12, p. I -XIII, 2000.

KUNZ, Elenor. . Se-Movimentar. In: GONZÄLES Fernando; FENSTERSEIFER, Paulo Evaldo. (orgs). Dicionário Crítico de Educação Física. ljuí: Editora Unijuí, 2005. p.383-386.

KUNZ, Elenor.Pedagogia do esporte, do movimento humano ou da educação Física?. In: KUNZ, Elenor, TREBELS, Andreas (orgs.). Educação Física CríticoEmancipatória. ĺjuí: Editora Unijuí, 2006. p. 11-22.

MERLEAU-PONTY, Maurice. Fenomenologia da Percepção. 1. ed.. São Paulo: Freitas Bastos. 1971.

Movimento, Porto Alegre, v. 16, n. 04, p. 263-290, outubro/dezembro de 2010. 
SANTIN, Silvino. Educação Física: Uma abordagem filosófica da corporeidade. Ijuí, Livraria UNIJUÍ, 1987.

SURDI, Aguinaldo Cesar. A Educação Física e o Movimento Humano Significativo: Uma Possibilidade Fenomenológica. Videira, SC: Êxito, 2010.

TREBELS, Andreas. A concepção dialógica do movimento humano: Uma teoria do se-movimentar. In: KUNZ, Elenor, TREBELS, Andreas (orgs.) Educação Física Crítico-Emancipatória. Editora Unijuí. ĺjuí, 2006. p. 23-48.

Recebido em: 03.09.2010

Aprovado em: 29.11.2010

Movimento, Porto Alegre, v. 16, n. 04, p. 263-290, outubro/dezembro de 2010. 